\title{
Integrating the Arts in Psychotherapy: Opening the Doors of Shared Creativity
}

\author{
Fran J. Levy
}

Published online: 24 April 2014

(C) The Author(s) 2014. This article is published with open access at Springerlink.com

\section{Introduction}

The focus of this paper is the integration of the arts in treatment with an emphasis on the creative interweaving of dance, art, writing, and drama as a way to unravel the mysteries of the past, embody the present, and explore aspirations and dreams for the future.

The theory behind this integration is that we are all different. Some people are more auditory; others more tactile. Some people experience and know the world more through the body and body movement while others rely on cognitive understanding. While this seems so simple, its effect on our work is profound. If we don't listen carefully to the expressive preferences of the people with whom we work, we will miss major opportunities for communication and growth. The words, analogies, images, and metaphors that our patients use often tell us what media will be most expressive for them.

Our empathic understanding of our patients and how to treat them is, I believe, inextricably connected to our comfort with, and clarity about, ourselves. As our expressive potentials are broadened and strengthened, our style of therapeutic interaction is also expanded. The more "languages" we have, the greater chance we will find the right language to "speak" with the ones we try to help.

I began integrating dance/movement therapy with psychodrama and art into a creative approach to psychotherapy in the early 1970 s at the Institute for Sociotherapy. I combined my training with Blanche Evan, who used dramatic enactment and creative imagery, with my training in psychodrama and psychodynamic psychotherapy with Robert Siroka and Ellen Siroka Robinson, and in art therapy with Jean Peterson. In the 1970s and 1980s at the Institute, therapists were exploring the use of psychodrama as a core structure to help organize the creative

\footnotetext{
F. J. Levy $(\bowtie)$

Brooklyn, NY, USA

e-mail: franjlevy@yahoo.com
} 
expression drawn from other art forms. This was the hub that gave me a huge push toward the work I do today.

I also integrated the pioneering research of Sydney Levy (1958a, 1958b). Levy, not a relative, originated the projective method known as the Levy-AnimalDrawing-Story method (LADS), which is used today by many clinical psychologists, along with other projective drawing methods such as Figure Drawing Analysis and the House-Tree-Person test (Hammer, 1958).

Levy was a trained psychoanalyst from the "old school" but with a new perspective. While many professionals with a similar background to Sidney Levy were frightened and skeptical of expressive therapies, he was a huge proponent.

I had the good fortune of learning projective methods through drawing from Levy, and I began using this as a regular part of my work. One case you may be familiar with that illustrates this work is in the book, Dance and Other Expressive Art Therapies: When words are not enough (Levy, Fried, \& Leventhal, 1995). The chapter is called, "Nameless, a Case of Multiplicity." If you read that case, you will see one woman's evolution through the stages of early bonding and symbiosis to separation-individuation both in her artwork and in her movements and interactions with me. The cases that follow also illustrate this process.

\section{Experiential: Visualization}

Since actions speak louder than words, let's try a brief exercise:

Take a minute to close your eyes and take a few deep breaths to center yourself. Now imagine for a moment that you are in a tug-of-war with someone or possibly some part of yourself. What do you see? Who is pulling whom? What is being said? Is anyone looking on? What does this onlooker see? Can you reverse roles and visualize yourself now on the other side? Take a moment to see the movement dialogue that is taking place. Okay, now open your eyes.

This exercise combines many forms of experiencing and can be moved in countless directions. It is visual. It encourages a dramatic acting out or polarization of internal experience. In the question, "Is anyone looking on?" the exercise invites the activation of an observing ego to help reflect on the inner drama.

An exercise like this takes a movement-oriented image and gives individuals the space to project their internal experiences into dramatic structures. The stage is set for creative acting out of conflicting roles and the release of energy that is tied up in the conflict. Some people discover that they are in a tug-of-war with another part of themselves or with a significant other. These insights can be moved into a dance improvisation, creative writing, or a drawing. Each medium helps to reveal and shed light on different aspects of an individual's personality. Often what surfaces was previously out of the individual's consciousness, or it was understood intellectually but without any depth of feeling. It is this deeper experience that opens the door for change. 
In a recent session, I asked one young woman to act out the tug-of-war image with an imaginary rope. I did this as I sensed in her conflicting feelings concerning a pending promotion at work. She was the brains behind this promotion and had helped to orchestrate it. She did the exercise and immediately got in touch with her extremely competent adult self pulling at one end, and a mischievous child acting alternately helplessly and aggressively at the other end. She quickly identified that this mischievous child was a part of herself. While she had been aware that this dichotomy existed within her, she had not experienced it quite so vividly, nor realized how severely this inner child was impacting her life. Acting out the conflict helped her to both see it more clearly and to release her from its grip.

This exercise started with creative visualization and then was used as a springboard for the unconscious, or semi-conscious, to become conscious. The dramatic structure (in this case the tug-of-war image) clarified the inner conflict by giving it a recognizable shape. The embodiment of the conflict allowed for emotional release, or catharsis, that paved the way for insight and the possibility of resolution. I have found more and more that the use of silence with eyes closed, breathing, and visualization combined with creative art expression, open doors to a deeper experience of the self.

\section{Brief Overview of the Arts and Their Functions}

The following is a brief overview of the various functions of dance/movement, visual arts, writing, and drama in an integrated arts psychotherapy approach. These concepts have been drawn from my clinical experience. You will see this integration and hear my rationale in the case material that follows. Visualization, as discussed above, should be included in this list of modalities (Levy, 1979, 2005; Levy, Fried, \& Leventhal, 1995).

\section{Dance/Movement}

There are innumerable ways to make use of body movement in psychotherapy. Within the framework of integrated arts psychotherapy, I use dance and movement primarily for release, embodiment, and processing of thoughts and feelings. This can be accomplished through spontaneous movement improvisation or more structured dance/movement experiences. Dance can be facilitated through visual imagery, meditation, music, drama, and words. Expressive dance takes that which is stored in the musculature, and/or in the mind, and externalizes it through body action. This includes the expression of conscious and unconscious material.

Movement helps individuals to bypass verbal defenses and to enter deeper realms of personal realization. Engaging the body through dance also helps people to access and process non-verbal events. This includes traumatic memories that may have been experienced but were not recorded verbally in the cognitive part of the brain (Levine, 1997; Scaer, 2007). Finally, for the purpose of this brief overview, body movement can help individuals who are stuck in their thoughts, and out of touch with their feelings, to reconnect and integrate mind and body. 


\section{Dramatic Polarization}

Jacob L. Moreno (Moreno \& Moreno, 1975), the father of psychodrama, believed that people experienced what he called action hunger, the need to express unresolved feelings. He created the psychodramatic stage as an arena for the exploration and expression of these feelings.

Psychodramatic dialogue is ideally suited for dealing with unresolved emotions and inner conflict. Drama encourages the expression of opposing points of view and the polarization of emotions. Dramatization can take place on many different levels. For example, I often ask individuals to draw two animals. One time a person drew a turtle and a tiger. I asked this individual to embody both animals and then asked if there was a movement dialogue between the animals. After the movement dialogue was over, I asked what these animals would say to each other if they were to speak. The individual realized that the turtle and the tiger were two different parts of herself as well as representing her mother and her father. A deeper understanding of the psychodynamics in this individual's life was reached, as was the desire to find a more comfortable middle ground within herself.

Psychodrama provides a structure within which all other all other art forms can be used. It provides a stage on which the conscious and unconscious can be projected and creatively worked with. The tug-of-war image, discussed earlier, and the "draw two animals" exercise used dramatic structures to tease out the psychodynamics within an individual. There are countless creative exercises that can lead to dramatic experiences such as these and facilitate expression, exploration, catharsis, and insight.

\section{Visual Art}

Drawing is also a projective technique that evokes psychological material and manifests it in a visual format. This enables one to step back from the finished product and reflect on it. While viewing one's own art, an individual is visually taking back in that which was projected. In this way, one is given an opportunity to reclaim one's own projections, making the unconscious conscious. This provides the necessary release from what has been repressed with the ultimate goal of providing insight and resolution.

I have found the use of visual arts, particularly drawing and painting, to be effective intermediary steps negotiating between the intensity of movement and the relative distance, for some people, of words. Creative modalities should be used with the intent of helping individuals to organize and express aspects of the self previously out of reach.

\section{Theoretical Underpinnings}

The following theoretical concepts explain the clinical work that I will discuss.

First, I'd like to cite Mahler's (1975) work on the two births of the infant. Mahler differentiated biological birth from psychological birth, (i.e., the separation- 
individuation process that continues to take place as part of the overall development of the child into adulthood). This process can also be looked at as a continuum with symbiosis at one end of the spectrum and separation-individuation at the other end. According to Mahler, in the symbiotic phase of development, individuals actually feel merged physically with parental figures. Their own separate thoughts, feelings, and body boundaries delineate over time.

Furthermore, we do not mature uniformly. Experiences and feelings from early phases of life continue to create ripples into adulthood (Freud, 1960/1909). This was illustrated in the tug-of-war example where the child self of my patient was fighting against the emerging adult.

Also on a continuum is the degree that individuals experience themselves either as fragmented and conflicted or as integrated and whole. Fragmentation often overlaps with symbiosis, and integration often overlaps with a healthy separation and maturation.

Also on the continuum are one's instinctive drives versus rules and regulations. On this continuum, unlike the others, the center area is the one that is in the healthiest range. According to Freud (1960), we are all divided between id instincts and superego restraints with the goal of finding a healthy negotiation between the two extremes.

In regard to the continuum concept, it is important to note that no one is completely at one end of the continuum or the other. We all exist somewhere between the extremes and we move back and forth depending on the given circumstances of our lives at any one time. All of these concepts are illustrated and clarified in the three cases that follow. All three cases demonstrate a severe rejection of aspects of parts of the self.

\section{Brenda: Loving the Tomboy}

Brenda was 23, living with her family and pursuing her masters degree. She was deeply depressed. Before coming to me she had been in verbal therapy but was totally frustrated. I saw her for three years in individual and group sessions. Brenda felt physically frozen and was petrified to do even the simplest movements. When I asked her to swing her leg, she started to do it and then stopped abruptly in a panic.

I asked Brenda about her childhood and particularly what she enjoyed doing. She said she loved to draw. She seemed upset by this statement, following it up by saying that her parents had put down her drawing ability and discouraged her.

Since movement was too provocative for her, I suggested that we start with drawing. She welcomed this option and chose the size paper she wanted and the colors she wanted. I encouraged her to just enjoy the use of color and allow her hand to move freely on the page, not worrying about the results. What occurred was exciting to witness. Her previously rigid body became animated and expressive. She sat on the floor and moved her upper body along with her hand and arm movements. Her movement repertoire expanded over time as she explored various shapes, colors, and rhythms. I supported her by offering her larger pieces of paper as she became ready to handle more space (Levy, 2005). 
After this experience Brenda said she thought she was ready to try moving again. Brenda tried head rolls and leg and arm swings but still with embarrassment. At times she asked me not to look at her while she moved. When I asked her why not, she said, "You'll see that I'm ugly." Kicking was the hardest movement for her.

We continued to draw in the sessions. By this time, Brenda and I had been working together for about four months. One day, at Brenda's suggestion, she and I painted a mural that included a group of kids playing baseball. On paper we playfully pretended to throw the ball by painting a ball in motion and similarly, batted the ball and ran the bases, using large sweeping lines on the page. Drawing became an animated experience that grew, gradually lifting more and more off the page. There were expressions of joy, laughter, competition, and self-assertion.

Since this experience became a drawing in motion, I suggested that we act out the mural together using the studio as our baseball field. Brenda was willing. To warm up, we began to throw an imaginary ball back and forth and then began to bat the imaginary ball. We tagged each other, yelled a lot, and generally had a great time. I had never seen Brenda so animated and fun-loving. Her previously very soft, childlike voice became deep, almost husky, and her passive defensive demeanor became assertive and playfully tenacious. She bullied me around and I fought back. When we finished, Brenda was still laughing. She said, "I haven't had this much fun since I was a child. I loved to play ball. I was a good athlete. I loved playing football with the boys. When I reached puberty, my parents stopped me from all of the activities that I loved."

Brenda's family was orthodox. They became more and more religious as she grew up and less and less tolerant of their daughter's behavior. This attitude paralyzed Brenda psychologically and physically. Her parents called her a tomboy and humiliated her amongst her peers. She had feelings of wanting to kill herself. In actuality, I don't believe she wanted to kill all of herself but rather the part of herself that was threatening her ability to receive love from her parents and the part of herself that she had learned, through them, to see as ugly and wrong.

When patients talk about wanting to kill themselves, we need to find out if they are expressing the desire to destroy a part of themselves that is frightening to them or a part they feel may be unacceptable to others. How do we help them to understand, accept, and handle the rejected part? This theme is present in all of today's cases. Expression through the arts in the presence of an empathic observer, or witness, is a powerful tool to help individuals to integrate their rejected parts and to help them on the road to healthy separation-individuation.

In an effort to help Brenda to accept and integrate the parts of her personality she had rejected, the parts she wanted to kill off, we spent time talking about her associations to gender. We addressed her preconceived ideas of what was expected of males as opposed to females. She realized that she had incorporated within herself her parents' judgmental and rigid attitudes concerning how she was allowed to act and what she could feel as a girl. I reassured her that girls love to rough house and play ball just as much as boys do, and it didn't mean that they were not really girls. I expressed to her that I thought it was terribly sad for a girl to have to give up all that fun to become some false image of being a lady. I also reassured Brenda that I loved playing ball with her and that we would do it again if she wanted (Levy, 2005). 
Brenda's masculine, tomboy energy, the part she kept secret, even from herself, had become the enemy. She tried to repress it. What had brought incredible joy to her as a child, now threatened to embarrass and humiliate her as an adult. When Brenda denied the part of her that loved sports and drawing, she not only lost the joy that those activities provided but also the feelings that those activities expressed. She lost access to the joyful, playful, and assertive aspects of her personality. Brenda emerged in our individual and group sessions as an extremely fun loving and warm young woman, caring and empathic to others. All of this was released when she got in touch with and was helped to enjoy and love her lost tomboy self.

\section{Chris: Living in a Pressure Cooker}

The following case of Chris, a young woman in her twenties diagnosed with schizophrenia, shows how the visual arts provided safe symbolic avenues of expression that were then embodied in movement, paving the way for the gradual integration of the self. This work lasted for three years and included weekly group and individual sessions.

Whereas Brenda locked her feelings in her body, Chris locked them in her mind.

Chris tried desperately to split off from her body and all emotion, particularly her sexual and aggressive drives, by creating a vivid fantasy life that she kept secretly in her thoughts. This complete repression of her libido and aggressive energies had dire consequences. She had been hospitalized several times for psychotic breaks in which inappropriate rage and sexually provocative behaviors had broken loose. She came to me after her release from the hospital. She walked into my office in a ghostlike, weightless, fashion. I knew I had to find a way, as quickly and carefully as possible, to help her to release and gradually integrate her mysterious and unmodulated emotions.

Chris created fantasy people and animals that held a great deal of secret sexual imagery. One imaginary person that she created she referred to as a sensual mother earth image that she called Ayla. Ayla, Chris said, was totally comfortable with her sexuality. This was in sharp contrast to how Chris felt about herself. About herself, she said, "I am a goody-goody and boring. I hate my perfect self." Chris expressed contempt for her dutiful self and wanted to be much more spirited and rebellious, more like her imaginary Ayla. I encouraged Chris to talk about Ayla to see if that would help her connect to her own sexual feelings. At this point, verbalization seemed the safest vehicle for expression, but for the most part her words were disconnected from her feelings. I did not want to jump into movement too quickly. Chris had vacated her body for a reason. She was defending against an overflow of emotion that had landed her in the hospital on more than one occasion. I wanted to respect her defenses.

Chris loved to draw and had a portfolio of her artwork. Her artwork had many images, from flowers and animals to explicit sexual imagery. I suggested that we draw in the session and begin with choosing images from nature. Initially she drew flowers. I asked her if she wanted to interpret her drawings in movement. She seemed eager to do this. With her hips she did small subtle sensual movements. She 
said that it felt really good to her to move. When she finished, she said in her very soft voice, that she felt more relaxed, more like herself.

Soon after we did this and other drawings that brought out her sensual side, provocative images appeared to her in our session. One spontaneous image that she had was of her mother scolding her for being sexually promiscuous. As a result of this image, several dramatic movement dialogues were triggered for Chris that she enacted through role-playing with her imagined mother. This was one of the first times that Chris actually expressed her anger at someone other than herself. In this session, she blamed her negative feelings about herself and her sexuality on her mother's "puritanical standards." Psychodramatically she played the role of her mother scolding her for being too sexual. She then reversed roles and played herself. The movement dialogue with her psychodramatic mother ended with Chris yelling at her mother, dancing in sensual ways in front of her, and declaring her sexual freedom. I watched and supported her expression but did not take on any role. I remained an empathic observer.

That night following the session, Chris called me in a panic. She was sobbing and said that it was an emergency. I told her to come to my office. In my office she began to talk to me but her convulsing sobs made it difficult for her to speak. In a very poignant moment, Chris told me that she remembered having sexual feelings for her father and hating her mother. We talked at length and I helped her to understand that these feelings were a natural part of growing up and were normal feelings. I spoke with her about the difference between thoughts, feelings and actions. I explained that we don't control thoughts and feelings, they just occur. The only thing we can control is our actions. I explained that she had not acted out her feelings with her father. Many sessions were spent subsequent to this event with me trying to help her to understand the difference between thoughts, feelings and actions and helping her to talk about her sexual feelings and feelings of shame.

Chris's experience demonstrates how something as simple as drawing a flower can provoke and reveal so much. It also demonstrates how important it is to expect the unexpected and to stay closely attuned to patients when they are working on themselves, no matter what the medium.

Chris was becoming more comfortable with expressive movement. She began to use more of the space in the room and was more confident. Her movement patterns were stronger and more defined. Because of this emerging strength and because of Chris's strong associations to the image of Ayla, I suggested that she draw Ayla; Chris was happy to do this. After she drew Ayla, I asked her if she wanted to find movements that would express Ayla through dance. She said she did. This time, when Chris danced, her movements were that of a young woman loving her sexuality and loving herself. She expressed liberation and joy.

Chris was grateful for the opportunity to embody Ayla. She expressed this gratitude by inviting me to join her on imaginary safaris into wild luscious jungles. She narrated our journeys through rich rain forests where we encountered numerous beautiful and exotic animals. Chris eventually integrated her visual and physical experience of herself through creative writing. She wrote stories about her imaginary travels and the things she saw along the way. We continued to use dance/ movement to interpret her stories and to help her to stay connected to her body. 
By having Chris become Ayla, I was inviting her to feel the feelings that she had kept secret and projected onto her imaginary friend and other elaborate images. By seeing her own drawings and then taking the images back into her body by way of the visual stimulation they provided, she was breathing life back into her body.

This method freed her from the pattern of secrecy, shame, and repression that had isolated her from herself and others most of her life. About this she wrote:

...I feel like all of the answers I could ever want are already inside of me but I translated them into imagery and symbols as a way to talk about them.... One way to bring my worlds together is through creative movement...by taking my imagery and translating it into the conscious expression of real tangible feelings.

While these methods can't cure her schizophrenia, they provided her with important tools that helped her live with her illness and better understand, and even enjoy, her own unique process.

\section{Connie: A Journey from Fragmentation to Integration}

This last case of Connie demonstrates how movement, art, drama, and writing work together to help in the separation-individuation process. I worked with Connie individually for seven years.

Connie started therapy with me in her late 30s feeling depressed and wanting to divorce her husband of 13 years, her "high school sweetheart," described as her "best friend." She had just moved out of the house that they had built together. She said that when she was in the house she always felt sick to her stomach, nauseous. These statements raised some serious questions in my mind. How could her husband be both her best friend and a person that made her feel so sick that she wanted to leave him? She had already moved out of the house. The answer to these questions came out in Connie's drawings, creative stories, and her expressive movements.

Once a year, I asked Connie to do three projective drawings for me and to write stories about them. Throughout our work, in addition to these diagnostic drawings she drew numerous expressive drawings.

Regarding the method of figure and animal drawing analysis (Hammer, 1958), the protocol for requesting projective drawings is as follows: When I ask for figure or animal drawings, I ask the individual to give me the name of the person or animal that is drawn. If it is an animal drawing, I ask what kind of animal it is. I also ask what the gender of the image in the drawing is and I request that a story about the drawing be written. The following interpretations of Connie's drawings were done in collaboration with my mentor, Sydney Levy (personal communications, 1980-1990).

\section{Connie's Projective Drawings}

\#1 Initial Drawing: "Lynn." My initial request was for Connie to draw a picture of a person. See if you can take a second to look at the drawing and to feel in your body 


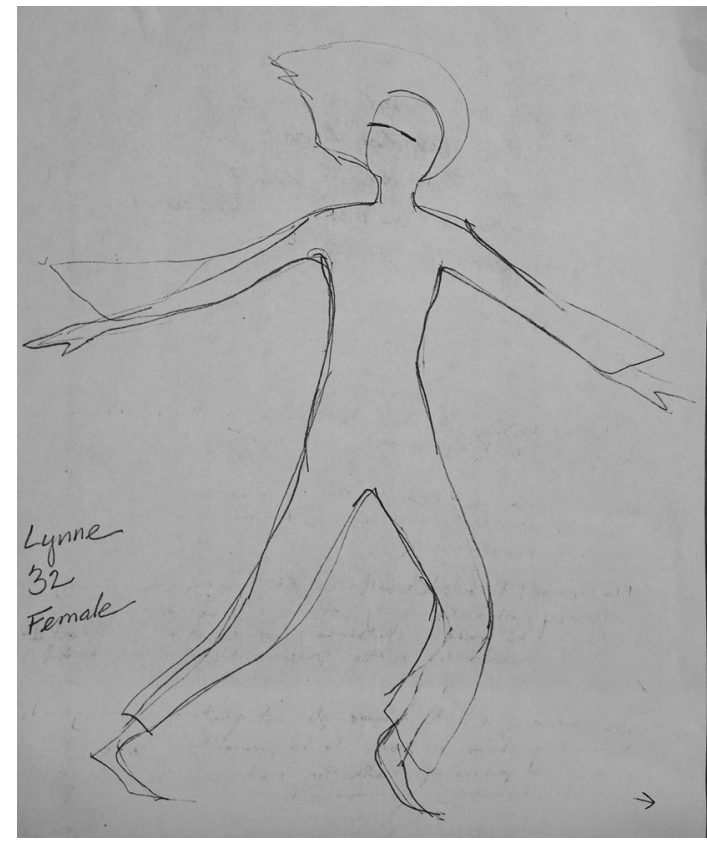

Fig. 1 Lynn

what this figure may be experiencing. You can stand to do this or just see it and feel it. As dance/movement therapists, we have a unique ability to feel what a drawing is telling us through our training in kinesthetic empathy. I have found that embodying the patient's images also tells me a lot.

If you look closely at the drawing of Lynn (see Fig. 1) you see that the cover over the figure's body is actually transparent. While this is a style today, it wasn't when this drawing was done. What appears vaguely to be clothing, is more like a double line around the body. The transparency and double line around the body usually represent an incomplete separation-individuation. The actual lines of the drawing are quite faint. This represents a lack of a strong sense of self.

In figure drawing analysis, the right side of the page represents leaving home (separation) and the left side symbolizes home (attachment). In this drawing, Lynn's body is moving in both directions at the same time. She appears to be trying to move forward but looking and leaning back to the home side of the page. She is also on her toes, which we know as dance/movement therapists suggests inadequate grounding. It is diagnostic that there is very little physical detail to her body. The figure has no mouth, nose, or ears and her eyes are closed. This figure is not fully developed.

This is the story Connie wrote after drawing Lynn, "Lynn is dancing like an angel in clouds. She doesn't need to see or speak, air carries her. She doesn't care where she is going. No past or future. She seems androgynous." This story and drawing tell us quite poignantly how Connie feels in the world. She blows with the wind and relies on outside forces to direct her, not her own perceptions. In short, she doesn't know who she is or where she is going. 


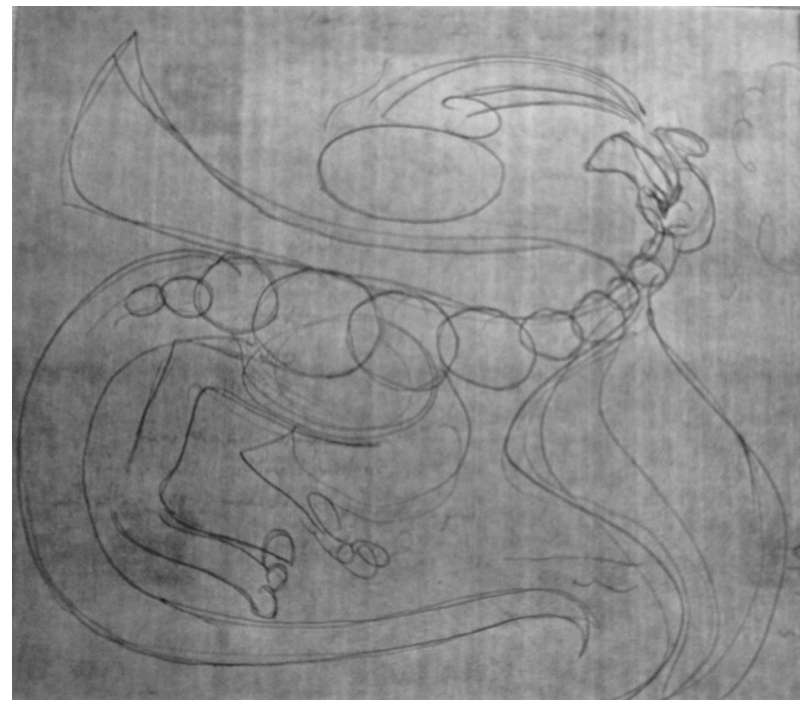

Fig. 2 The Dragon that Crisps

Connie was very depressed when she started treatment and didn't understand her desperate need to break away from her marriage or why she felt nauseous in the house that she and her husband built. She was deeply lonely and felt alienated from herself, her family, and her friends. Like Chris, Connie had a distant quality to her and could not feel or discuss her emotions. Her frustration was apparent. Often she just stared at me. Her eyes begged me to help her. Connie's next drawing and story about a dragon are packed with important information.

\#2 Drawing "The Dragon that crisps." The story Connie wrote about her dragon reads:

This dragon stirs up the air with its wings and tail. It spits fire and can crisp something in a second. It is very friendly but spends most of its time alone in the air watching the earth below. It is afraid it might crisp a person if it went too close.

Through this drawing (see Fig. 2), Connie presents us with her dilemmas and conflicts. The dragon is friendly, but spits fire if you get too close. She's lonely but afraid to land and connect to others. Some things to notice in the drawing: Similar to the drawing of Lynn, this drawing is faintly drawn and ungrounded. If you look closely, you will see transparency and a lack of clear boundaries. I had to darken the image for you to see it and that is why the page appears shaded. The dragon is a huge animal, taking up the entire page. The large size and intricate, but chaotic, detail indicates that she is preoccupied with all of the feelings and thoughts going on inside of her, but feels unfocused and ineffective in life. Her story tells us that she is afraid to join others on earth for fear of hurting them. Because so much of her feeling has been bottled up, she experiences confusion, disorganization, and 
depression. Continuing on this trajectory could lead to psychosis. She needs desperately to be heard and understood, but experiences intense frustration and difficulty expressing herself. Words were not the way to reach Connie. She could tell me a lot more through her drawings and, eventually, through movement.

I did not ask her to embody the drawing of the dragon because I did not feel there was a clear movement intention in the drawing. The energy of the dragon was too disorganized, and I felt the movements it would trigger would further unravel her. Also, Connie's story made it clear that she was afraid of the fire in her. I did not think that she was ready to experience the burning rage that she had creatively expressed. If you look closely, you can see the dragon breathing fire and the dragon's long tail. Both are expressions of rage. Her rage was being expressed in the drawing and in the story, but she wasn't fully conscious of it.

Connie's ego was clearly fragile. As with Chris, I had to find safe ways to help her feel and understand her emotions. I began by asking her about her husband and about her childhood. She described her father as an angry man, intense and seething with rage. She said that he drank too much and only related to her through his negativity, always asking intrusive questions, criticizing, and controlling her. She described her mother as being distant and unavailable. Her mother made quilts and could spend hour after hour quilting alone in her studio. Connie felt her mother harbored a smoldering rage that kept her from relating lovingly or spontaneously to the family.

Connie took violin and dance lessons as a child and was told to perform for the family's relatives and friends. She was an 'A' student and went to church regularly with her parents, always wearing dresses that her mother made for her. She remembered being the "perfect" child but feeling like a puppet with her parents pulling the strings.

Connie described being out of touch with feelings in her daily life. Because she was so emotionally distant, I would ask her what happened during the week and then encourage her to tell me in detail about specific events that had occurred. When she discussed her activities I observed, through her body and eye movements, tension around particular events and interactions. When I asked her to physically reconstruct and dramatically act out these events through role-playing, she was receptive. By doing this with me, in a safe space where she did not feel judged or threatened, she was able to get in touch with the feelings and conflicts that were troubling her. For example, Connie was a professional in her community and was looked up to as a role model and healer. But deep down Connie felt irritated by the excessive needs of particular clients and some of her friends. She felt at times overwhelmed and irritated at the role of nurturer that she was cast in. We were able to use these situations to help her to get in touch with her feelings.

The movement dialogues helped Connie to become more introspective and gave her the time she needed to feel her emotions, particularly her anger. Starting with dramatic dialogues that focused on the present was a way to help her to build a tolerance for feeling. This work paved the way for the deeper, core work that still needed to be done around her experiences as a child with an alcoholic father and an emotionally distant mother. The present often reflects the past but is a safer place to begin the work. 
When Connie seemed ready, I asked her to pretend she was going into the house she and her husband had built and to give me a tour of the different rooms. Then I asked her to show me in movement what she experienced in each room. What emerged were her feelings of inferiority, invisibility, and competition with her husband. Connie said, "He is always right. He has it all together and makes me feel like shit. I feel like a prisoner in my house... I feel invisible." By having Connie visualize and recreate the scene that she said was making her nauseous, the psychodramatic stage was set for her to re-experience what she felt, and explore why she needed to get away from her husband.

Now Connie's real feelings were able to come out. "He is my best friend" is what she told herself and others, but inside she harbored deep feelings of resentment and jealousy. She was envious of the power he seemed to possess and was angry at the way he made her feel about herself. She felt oppressed and was sitting on a great deal of rage, some of which she was able to release through the dramatic movement that she did while imagining herself in their house.

Eventually, through this work, she realized how much her husband represented her father. She felt nauseous when she entered the home because she couldn't stomach the feelings anymore. She wanted to get rid of them, but since they were attached to her husband, she had to get rid of him. As we saw in the drawing of Lynn, her own conflicting drives, the drive to stay attached versus the drive to separate, were also tearing her apart and underlying much of her depression.

\#3 Drawing: Unnamed. This drawing has numerous interpretations. It is hard to see because it was lightly drawn, like the drawings of the dragon and Lynn. The faintness of the drawing, along with the overall lack of detail and amorphous shapes, indicate a lack of distinguishing features, an incomplete identity. One has the impression of an undeveloped self partially attached to another undeveloped self. The large clothing hiding the body could also indicate the desire to hide parts of the self and feelings. The hands, which usually represent communication and reaching out, are depicted with unusual detail given the overall lack of detail in the drawing, but are stuck within the slits in the clothes. This suggests an inability to reach out to others as well as a possible fear of what the hands will do if they are freed. There appears to be a repressed action wanting expression. If you compare this drawing (see Fig. 3) to that of Lynn (see Fig. 1), you will see the beginnings of separationindividuation. Lynn (see Fig. 1) was completely merged with another with no delineation. This drawing has two heads and in this case two heads are better than one.

\#4 Drawing: Unnamed. Try to become this figure (see Fig. 4). What do you feel? This drawing was done around the time that Connie was struggling with the idea of going to medical school. Her parents were pushing her to go, and she rationalized that it was a good idea. The double image around the shoulders indicates that she does not feel separate from another. The merging discussed earlier has reappeared. On the continuum from symbiosis to separation, she has temporarily moved backward. Deep down, she hoped that medical school would bring her the respect she craved from her parents; but instead, filling out the applications aroused so much conflict in her that she became deeply depressed. As the drawing suggests, she is completely back in her parents' grips, living their dreams, not hers. 


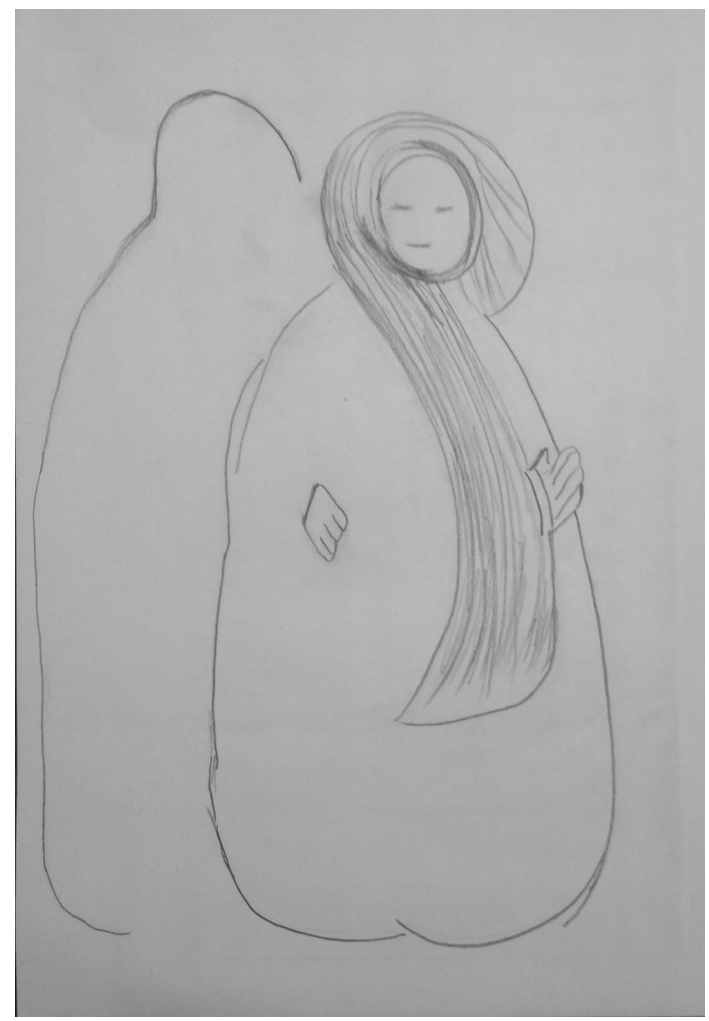

Fig. 3

In figure drawing analysis, it is significant when individuals put the figures' hands in their pockets. It symbolizes hiding certain emotions or thoughts from the outside world and/or from themselves. Connie was hiding her anger at feeling controlled, but was unaware of it at this time. Drawings, like dreams, express metaphors. For example, in this drawing the figure is being "pushed into a corner," and appears "all bottled up."

We were able to use this drawing for movement improvisation and role-playing. She became the person pushed back into a corner with shoulders lifted and tense. She then moved in such a way as to try to release herself from the restraints depicted in the image. The words, "get off my back" came to her consciousness and she improvised a dance around this feeling. Through her dance she got in touch with her father admonishing her for not being serious about her schoolwork and for wasting time.

This image of Connie's father ushered in a movement dialogue with him in which she expressed in words and movement how upset she was that her father never seemed to think that she was doing enough. She remembered him, on numerous occasions, bursting into her bedroom in a rage. She also expressed her disappointment with herself for not fighting back sooner. 


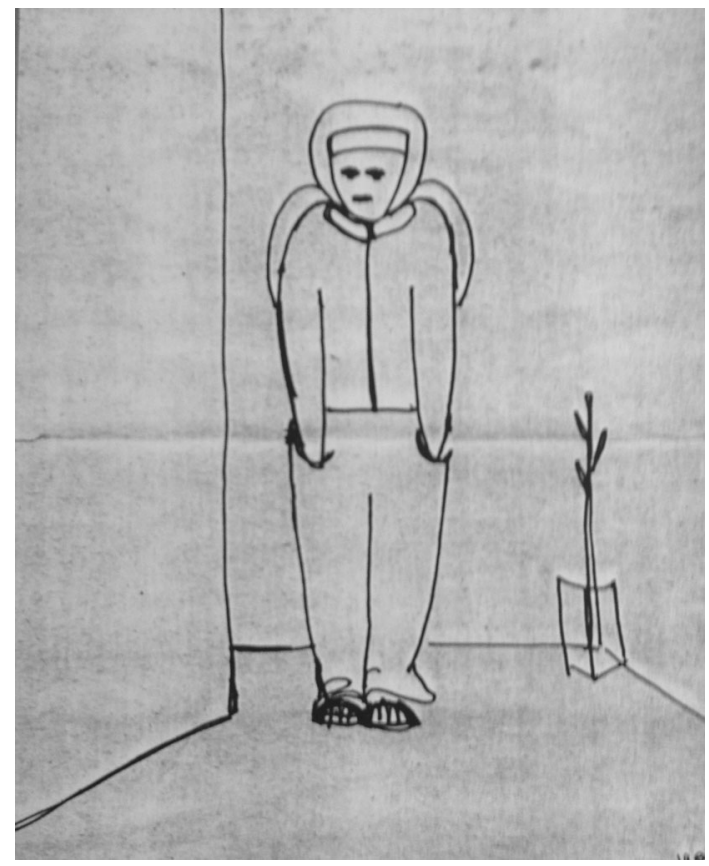

Fig. 4

With great strength in her movements, she took her hands out of her pockets and pushed both of her parents back as if trying to make space for her self. By becoming the image in the drawing, she could no longer hide from her internal experience of feeling controlled and manipulated. For the first time she was able to identify and embody the anger that had been inside of her and had overwhelmed her for so many years, depleting her energy and frightening her. This marked a strong move in the direction of separation-individuation for Connie.

While Connie knew on some level that this conflict with her parents existed, she was so locked into it that it could unwittingly reappear and throw her off balance. The movement served to first exaggerate the conflict, so she could clearly see it, and then to release her from it on both physical and emotional levels.

That is the beauty of the work. The arts, used in combination, eventually reveal the patient's unspoken story. The therapist, in the role of witness, validates the person's experience and encourages further exploration. This does not mean that how the patient experienced his or her life is exactly as it happened; but the work must begin with the individual's experience of reality and then can move on. Within the framework of the therapeutic relationship, the arts help to gently peel away the individual's defenses and make available the self that has been either denied or is undeveloped.

\#5 Drawing: "Mostly Nasty Monkey." Can you experience in your body the feelings that this drawing is expressing? Connie named this animal "Mostly Nasty Monkey." Here you see Connie's anger and you can feel that it wants to leap out 


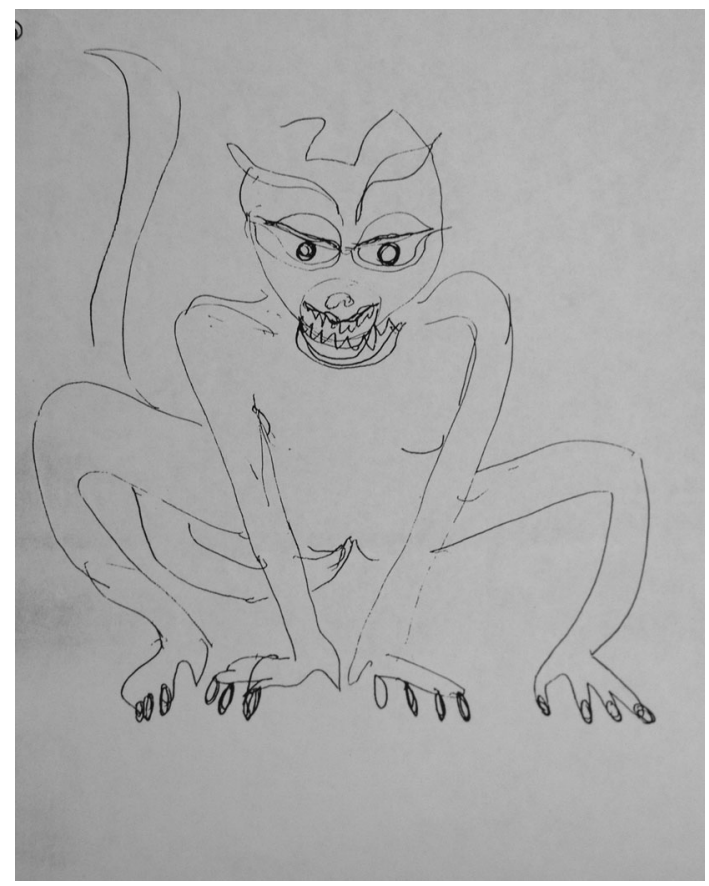

Fig. 5 Mostly Nasty Monkey

(see Fig. 5). This drawing was her response to a visit to her family in which her mother had touched her breast while expressing her feeling that Connie's sweater was too revealing. This enraged Connie. She experienced the touch as her mother's way of reminding her that she (the mother) was in control of Connie.

Note the clarity of expression in this drawing as compared to the other drawings. The animal is not a fantasy animal like the dragon. Moreover, compared to the dragon, the features in this animal are fairly well rationalized (realistic), indicating that Connie is more in touch with reality. More realistic facial details and functional extremities have replaced imaginary and ambiguous symbols. The eyes are not closed as they were in previous drawings. The emphasis on the long tail again symbolizes rage and becomes a theme for her in subsequent drawings. The mouth and eyes display a fiery rage. This drawing is clearly delineated, organized, and grounded. It has a palpable movement intent. The broken line around the top of the monkey's head indicates that she still feels overwhelmed by thoughts and feelings that she cannot completely contain.

Because of the overall strengths in the drawing, I felt it was safe for Connie to interpret "Mostly Nasty Monkey" in dance. Connie immediately began with movements that looked exactly like the drawing. She released many blood-curdling screams as she moved quickly and deftly around the room. I must admit I had some concerns. I wondered if I had moved the work too quickly into action and wondered if she could contain the fury she felt. It all worked out, and Connie proved to me that 


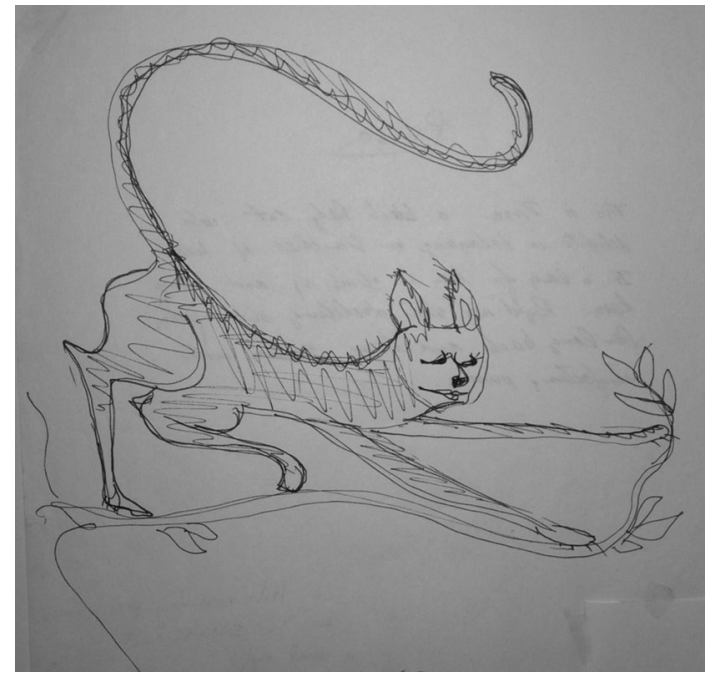

Fig. 6 Wild Lady Cat

she could handle this intense expression and that she desperately needed to have this release. Afterwards, she said she felt great. I could see the positive reaction in her face and eyes. She was more fully present with me than usual and expressed an unusual readiness to face the rest of the day.

\#6 Drawing: "Wild Lady Cat." Look at this drawing and feel it with your body (see Fig. 6). You can feel the change that is taking place in Connie. Connie called this animal "Wild Lady Cat." It is grounded, well rationalized, and has some relationship to the environment (the branch). It is not a fantasy animal. The body of the cat has boundaries, is organized, and there are facial features. It differs from "Mostly Nasty Monkey" in that a more graceful and assertive energy is replacing the raw rage and aggression of "Mostly Nasty Monkey" and the chaotic, ineffective and ungrounded rage of the dragon. The top of the head of "Wild Lady Cat" is closed, indicating that Connie is more able to integrate her thoughts and feelings within her body boundaries and within her mind. The facial features of this animal are much more relaxed and exist harmoniously with the rest of the cat's body. This drawing has a clear movement message and prompted an assertive and pleasurable dance in which Connie was able to reach out into space and bring back what she needed in movements that were self-nurturing.

What happened next in the therapy and the drawing was exciting. Eventually Connie drew both of her parents as realistic figures that were separate from her. We had done this projective drawing method for years but this was the first time Connie drew her parents as separate beings and not merged amorphous images. I did not tell her to draw her parents. I asked what I always had, for a drawing of a person. Connie was ready to externalize and clarify the images of her father and her mother through art. 


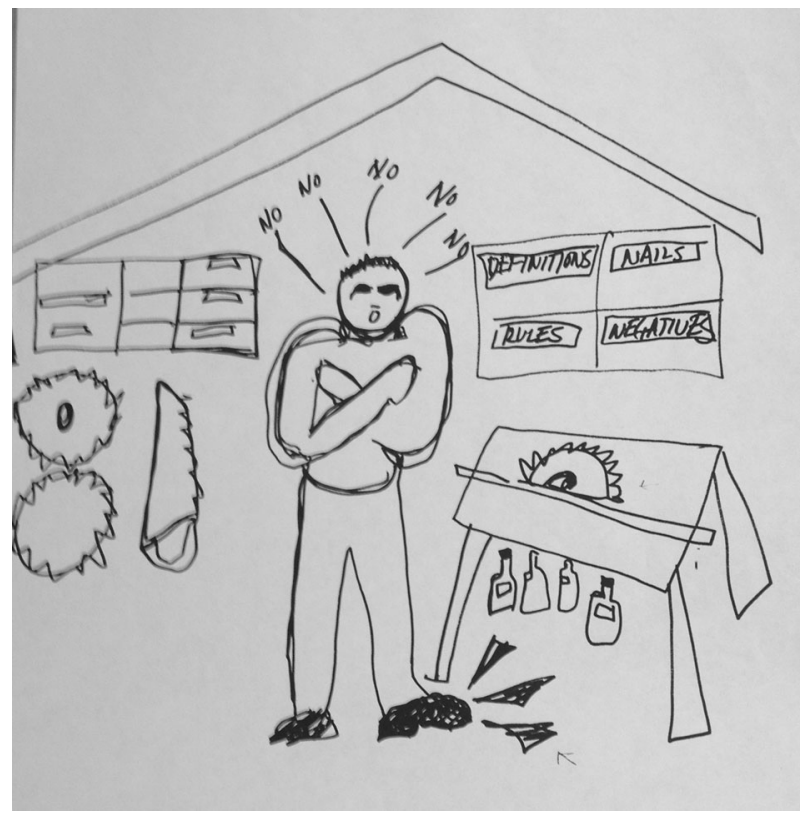

Fig. 7 Father

\# 7 Drawing: "Father." A quick look at the details in this drawing of her father shows you that Connie is now able to see and experience her father through her own eyes (see Fig. 7). She told the story of her father on paper. In psychodynamic terms she externalized the negative internalized object of her father. Her punitive superego, the part of her that hated and judged herself for not being "a better person," was largely the result of her internal dialogues with her critical father.

In reaction to this drawing, Connie created a movement dialogue with her father where she embodied her father and role-played an interaction with him that she directed. She took on her father's aggressive and hostile stance, that she had so clearly depicted in the drawing. In the role of her father, Connie became an angry man, and shouted out the words she had written, "NO, NO, NO, NO, NO."

By Connie acting out her father's anger, she was able to free herself from his rage; the rage she had internalized and that had become her own. Anger filled the spot that love should have taken. Without the blanket of anger, there was no blanket at all. This rage was now being released and symbolically given back to its rightful owner. Interestingly, Connie puts some double lines around the father's upper body and there is some resemblance between this figure and Fig. \#4.

\#8 Drawing: "Crying Bird." When I asked Connie to draw an animal, this is what she drew (see Fig. 8). This drawing was done the same day that she drew the father and mother drawings. Her mother appears in small scale in the bird drawing on the left. Connie drew her mother with a stiff angular jaw that she said depicted her mother's passive, but pervasive, gripping rage. 


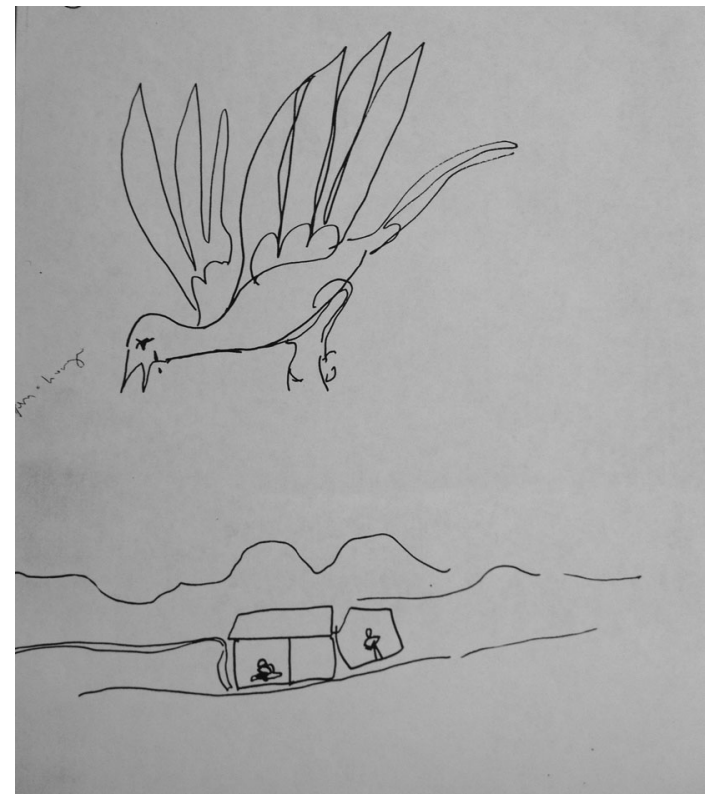

Fig. 8 Crying Bird

About this drawing she wrote, "the bird is crying and hungry, sad because she knows she has to leave home. She can't land." In this drawing, the bird, Connie explains, is flying over the house that Connie grew up in. She depicts her mother and father fairly small. They are isolated in their own individual spaces. She realizes that she is the bird and in order for her to find what she needs in life, she must fly away.

Connie cried as she drew and wrote this story. In words, she expressed the depth of her loneliness. We looked at the drawing together and an empathic sharing took place as we both acknowledged how far she had come and how clear the drawing was. She knew she had to separate from her parents and find "her own home," a comfortable place within herself.

\#9 Drawing: "Woman with Snakes." The final drawing speaks for itself. This figure depicts an individual who feels strong, empowered, and proud (see Fig. 9). The figure expresses a desire to be seen and accepted as a woman. Connie had told me that she was petrified of snakes. In this drawing, she takes control and masters her fears. I will juxtapose the first drawing of Lynn, Fig. \#1 (see Fig. 1), with this final drawing, Fig. \#9.

Interestingly, there is still the residual of transparency, as there was in the drawing of Lynn, Fig. \#1. This can be seen in the way Connie drew the clothing so that you can see the outline of the figure's body underneath. In keeping with the continuum theory of growth and change that I spoke of earlier, and the idea that we do not mature uniformly, Connie has grown, but keeps some earlier aspects of her development (Freud, 1960/1909; Mahler, 1975). What has changed is the intensity of the symbiotic fragmentation and dissociation that she experienced initially. The 
a

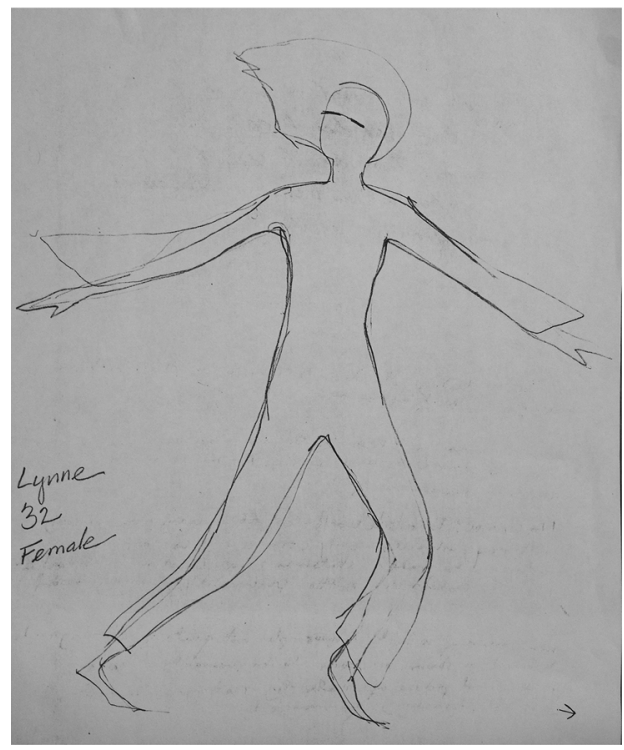

b

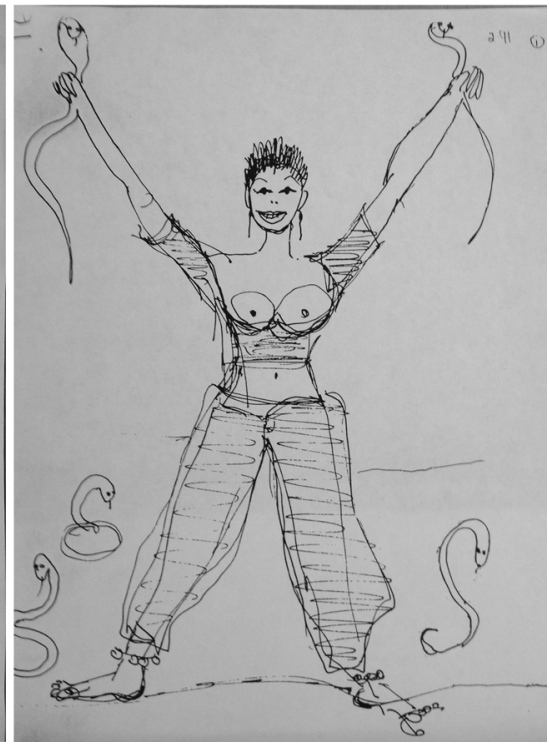

Fig. 9 a Lynn, b Woman with Snakes

transparency that still exists reminds us that clinically Connie is still vulnerable to the will of others overtaking her, and she may need shoring up of her strengths from time to time, depending on the circumstances in her life.

Years of creative expressive work had to be done to help Connie to organize and become comfortable with her true feelings. Like Brenda, she felt shame and feared the loss of her primary attachments to her family if she became fully independent. Like Brenda and Chris, Connie had to integrate aspects of herself that she had judged as bad and from which she had dissociated. All three individuals needed to externalize and separate from the negative introjections that had been controlling them. This separation opened the doors to self-acceptance and personal freedom. This does not mean that they had to end their relationship with their actual parents but, rather, they had to find ways to interact with them that did not result in oppressing themselves.

\section{Summary}

Genuine insight requires a physical release of energy. Without this release, the treatment runs the risk of becoming overly intellectualized and without substance. This is what makes the action-oriented, embodied approaches to therapy so vital. In all forms of psychodynamic psychotherapy, starting at the level of expression that is most available to, and constructive for, the client is essential for a positive and integrated resolution.

The issue of separation-individuation versus symbiosis is clearly seen in all of the cases presented. The move on the continuum from repression, dissociation, and 
fragmentation to self-acceptance and integration of the self is also apparent. Finally, on the continuum from pure instinctive drives to critical superego restraints, each individual used creativity to negotiate internal drives and to deepen their understanding of their own process. The struggles of these individuals are not over, but the work we did together gave each of them a strong foothold for the future.

For some, the struggle is much greater than for others. While everyone's story and personality attributes are different, the road to self-realization and individuation is universal and can go on for a lifetime. The arts, when used in combination in the presence of an empathic observer, help to pave that road. Therapists find their own unique ways of combining the arts into healing experiences. Most importantly, we must listen carefully to our patients and let them teach us what they need and how to reach them. If we listen, we will grow along with them. Finally, but most importantly, in all healing work, our empathy and understanding, love and caring, are our strongest tools.

Open Access This article is distributed under the terms of the Creative Commons Attribution License which permits any use, distribution, and reproduction in any medium, provided the original author(s) and the source are credited.

\section{References}

Freud, S. (1960). The psychopathology of everyday life. In J. Strachey (Ed. and Trans.), The standard edition of the complete psychological works of Sigmund Freud (Vol. VI). London: Hogarth. (Original work published 1909.)

Hammer, E. (1958). The clinical application of projective drawings. Springfield, IL: Charles C. Thomas. Levine, P. (1997). Waking the tiger: Healing trauma. Berkeley, CA: North Atlantic Books.

Levy, S. (1958a). Projective figure drawing. In E. Hammer (Ed.), The clinical application of projective drawings (pp. 83-112). Springfield, IL: Charles C. Thomas.

Levy, S. (1958b). Symbolism in animal drawings. In E. Hammer (Ed.), The clinical application of projective drawings (pp. 311-343). Springfield, IL: Charles C. Thomas.

Levy, F. J. (1979). Psychodramatic movement therapy: A sorting out process. American Journal of Dance Therapy, 3(1), 32-42.

Levy, F. J. (2005). Dance movement therapy: A healing art. Reston, VA: American Alliance for Health, Physical Education, Recreation and Dance.

Levy, F. J., Fried, J. P., \& Leventhal, F. (1995). Dance and other expressive art therapies: When words are not enough. New York: Routledge.

Mahler, M. (1975). On human symbiosis and the vicissitudes of individuation. New York: International University Press.

Moreno, J. L., \& Moreno, Z. T. (1975). Psychodrama: Action therapy and principles of practice (Vol. III). New York: Beacon House.

Scaer, R. C. (2007). The body bears the burden: Trauma, dissociation, and disease. New York: Hawthorn Medical Press.

\section{Fran J. Levy}

received her doctorate in the Integration of the Arts in Psychotherapy. She is a board certified dance/ movement therapist, psychodramatist and a diplomate in the New York State Society for Clinical Social Work. Dr. Levy is also a protégé of Sydney Levy, Ph.D. in his pioneering work in projective drawing and psychodynamic psychotherapy. Dr. Levy has been creatively interweaving the arts into a cohesive form of psychotherapy for over 30 years. She is the author of Dance Movement Therapy: A healing art (AAHPERD, 2005) and senior editor of Dance and Other Expressive Art Therapies: When words are not 
enough (Routledge Press, 1995). Her books have been translated into Korean and Chinese, will be translated into Japanese, and are used as textbooks for graduate and undergraduate programs in the United States and abroad. Dr. Levy teaches internationally and has her private practice in Brooklyn, New York. 